\section{Cuidar e Educar Criança Pequena para Valores: Um Ato de Amor, Justiça e Bondade}

\author{
Maria Souza dos Santos* \\ Jordana Wruck Timm** \\ Milena Cristina Aragão Ribeiro de Souza***
}

\section{Resumo}

Pensar no cuidado e na educação das crianças pequenas é primordial, tendo em vista que toda boa "construção" depende de uma base sólida, o que não difere em nós humanos, sendo na primeira infância a formação dos futuros adultos. O objetivo do artigo é compreender a educação baseada em valores, a fim de desenvolver na criança pequena uma atitude de gradual avanço no sentido da autonomia, da responsabilidade em assumir seu próprio desenvolvimento, buscando uma convivência social harmoniosa, tendo como base os princípios do amor, justiça e bondade. A metodologia empregada consiste nas pesquisas bibliográficas, com a realização de leituras flutuantes em artigos e na busca por referenciais teóricos nos livros, bem como, foram realizadas Rodas de Conversa com o propósito de realizar a coleta de dados. Com as informações obtidas concluímos que há necessidade de profissionais comprometidos com a mudança, dispostos a cuidar e educar para valores, visando uma infância meIhor e consequentemente um mundo mais pacífico.

Palavras-chave: Criança pequena; Cuidar/educar; Valores.

\section{Education and Care For Little Child Values: an Act of Love, Kindness and Justice}

\section{Abstract}

Thinking in the care and education of young children is essential in order that all good "construction" depends on a solid foundation, which does not differ in us humans, and early childhood training of future adults. The aim of this paper is to understand the values-based education, to develop in young children an attitude of gradual progress towards autonomy, assuming responsibility for their own development, seeking social harmony, based on the principles of love, justice and goodness. The methodology consists of the literature searches, with the realization of floating reading articles and the search for reference theoretician in the books. With the information obtained we conclude that there is need for professionals committed to change, willing to care for and educate for values, seeking a better childhood and consequently a more peaceful world.

Keywords: Young children, Care/education; Values.

\footnotetext{
* Mestranda em Educação pela Pontifícia Universidade Católica do Rio Grande do Sul (PUC/RS). Especialista em Gestão de Pessoas. Graduada em Letras e Pedagogia. E-mail: irmaria_souza@hotmail.com

** Mestranda em Educação pela Universidade de Caxias do Sul (UCS). Bolsista PROSUP/CAPES. Especialista em Psicopedagogia. Graduada em Pedagogia. E-mail: jordanawruck@hotmail.com

** Doutoranda em Educação pela Universidade Federal de Sergipe (UFS). Mestre em Educação pela Universidade de Caxias do Sul (UCS). Graduada em Psicologia. Bolsista FAPITEC/SE. E-mail: mi.aragao@ yahoo.com.br
} 


\section{Palavras iniciais}

O momento histórico em que vivemos está sendo marcado por diversas formas de violência tanto em nível familiar quanto pessoal. Várias são as causas destas ondas de violência. Podemos citar: as mudanças estruturais e organizacionais vividas pela familia, hoje; o esvaziamento de uma cultura de valores e solidariedade, o hedonismo, entre tantos outros.

Diante deste cenário onde as violências sociais constituem um grande desafio para a educação contemporânea, surge nosso questionamento: "como cuidar e educar as crianças pequenas fortalecendo-as para o enfrentamento das questões inerentes à vida?". Por isso, pesquisar a temática da infância na atualidade supõe um entendimento das diferentes representações que as crianças receberam no decorrer da história. Nesta pesquisa pretendemos abordar questões relativas à criança pequena, sobretudo, na esfera escolar.

Com este inquietamento e com a escrita deste texto objetivamos compreender a educação baseada em valores a fim de desenvolver na criança pequena uma atitude de gradual avanço no sentido da autonomia, da responsabilidade em assumir seu próprio desenvolvimento, buscando uma convivência social harmoniosa tendo como base os princípios do amor, justiça e bondade. Além de, analisar a importância de uma educação para valores recebida em classes de Educação Infantil e pesquisar o que se tem escrito até o momento sobre este assunto, refletir e apresentar as ideias mais relevantes encontradas.

O interesse por desenvolver esta pesquisa sobre a importância de uma educação baseada em valores para crianças pequenas surgiu a partir da trajetória da pesquisadora, docente na educação infantil e mestranda em educação da PUCRS, de vinte e cinco anos de magistério, dentre estes, nove anos dedicados exclusivamente à Educação Infantil na Periferia de Porecatu - PR e na Vila Farrapos, em Porto Alegre - RS.

Outro fator relevante foi a atuação da pesquisadora como Conselheira do CEDICA (Conselho Estadual dos Direitos da Criança e Adolescentes), no Estado do Rio
Grande do Sul (Gestão 2009-2011), onde pôde conviver com situações de adolescentes em conflitos com a Lei e de tentativa de reabilitação dos mesmos, geralmente internos da FASE (Fundação de Atendimento Sócio Educativo), e provindos de famílias em que fragilidade dos laços afetivos e a não-afirmação de valores vivenciados na infância e adolescência os levam a ter atitudes explícitas de violência. Como descrito, a escrita deste baseia-se na atuação da autora, a qual durante a realização do mestrado cursou duas cadeiras junto com a co-autora, a mesma tendo conhecimento do projeto de pesquisa e tendo experiência com a educação infantil, interessou-se em descobrir mais e poder apresentar os resultados provenientes das buscas.

Num tempo em que a aparência vale mais do que a essência e a competição impera nos relacionamentos, é imprescindível falar com nossas crianças de companheirismo, amizade e amor. (Chalita, 2003)

Acreditando na urgência de uma educação baseada em valores desde a educação infantil a fim de que as crianças pequenas encontrem novos espaços de socialização e construção de sua identidade, a pesquisadora ingressou no Programa de Pós Graduação da PUCRS como aluna de Mestrado em Educação com a intenção de realizar uma pesquisa que tem o intuito de aprofundar a temática "educação de criança pequena para valores por meio de uma práxis de amor, justiça e bondade".

Vale ressaltar que a pesquisa se sustenta pelo método da busca bibliográfica, com leituras flutuantes em artigos e na busca por referenciais teóricos nos livros, assim como, foram realizadas Rodas de Conversa com o propósito de coletar dados empíricos para a escrita do presente texto.

\section{Definindo alguns conceitos}

O título deste artigo "Cuidar e educar criança pequena para valores: um ato de amor, justiça e bondade" expressa às convicções das pesquisadoras de que os primeiros anos de vida de uma criança são fundamentais para o seu desenvolvimento em todos os níveis: cognitivo, social, físico, espiritual e afetivo. Faz-se necessário 
evidenciar algumas significações dos principais termos utilizados nesta produção. $\mathrm{O}$ eixo norteador desta pesquisa será a compreensão do processo do desenvolvimento infantil com base no cuidado e suas dimensões numa educação baseada em valores, sobretudo o amor, a justiça e a bondade.

A palavra "cuidar" é muito empregada na área da saúde. O binômio educação e cuidado já começa a aparecer nas produções sobre a infância. Neste estudo pretende-se aprofundar o sentido da palavra cuidar em educação, sobretudo as dimensões do cuidado, segundo Costa (2002): autocuidado, altercuidado, ecocuidado e transcuidado. O autor define o autocuidado como "um conceito em evolução".

A palavra "cuidado" vem do latim cogitare-cogitatus e significa cura: cogitar, pensar. Diversos autores ajudam a compreender o termo cuidar. Pode-se destacar: Cavalcanti (2004); Candiotto (2008); Dalbosco (2006); Frota, Albuquerque e Linard (2007) e outros. Boff (2008), destaca uma visão mais humanísitca de cuidado.

Candiotto (2008) afirma que o cuidado "diz respeito à atitude diferente consigo, com os outros e com o mundo; indica a conversão do olhar do exterior para o próprio interior como modo de exercer a vigilância contínua do que acontece nos pensamentos". Afirma, também, que

O cuidado refere-se à arte de viver, a ser desenvolvida ao longo da existência, desdobrando-se nas funções de luta (preparando para suportar eventuais acidentes, infelicidades e desgraças que lhe possam ocorrer), de crítica (para corrigir os maus hábitos) e de terapia (tarefa fundamental do cuidado de si, o saber cuidar do corpo e da alma). (Candiotto, 2008).

Waldow, pesquisadora da área da enfermagem define:

Cuidado é um processo, um modo se relacionar com alguém que envolve desenvolvimento e cresce em confiança mútua, provocando uma profunda e qualitativa transformação no relacionamento. [...] é ajudar o outro crescer e se realizar. (Waldow, 2004).
Costa e Lima (2002) afirmam ainda: "outra dimensão inovadora, em relação à qual se publica muito pouco no Brasil, encontra-se na abordagem da questão do autocuidado". Eles defendem o "autocuidado como valorização da vida em todas as suas dimensões".

Estes mesmos autores (2002) destacam a importância de uma educação para valores para que, quando jovens, além das oportunidades recebidas, o jovem "saiba decidir o rumo a seguir, ou seja, saiba tomar decisões fundamentadas, tenha bons critérios para avaliar e decidir".

Algumas novas tendências em educação vêm apontando para mudanças significativas para o século XXI. Jacques Delors, no relatório: Educação, um Tesouro a Descobrir (1998), aponta caminhos para uma educação transformadora que além de cuidar do corpo preocupa-se com o cuidado dos sentimentos.

A educação necessária para empreender esta transformação, ou seja, esse amplo processo de re-significação dos relacionamentos básicos do ser humano deverá ser um processo educativo capaz de mudar as maneiras de decidir e agir. Para suscitar as mudanças nos processos de decisão e ação das pessoas, será necessário proceder a uma ampla, profunda e autêntica educação para valores. (Costa, 2005).

A educação para valores deve atentar para aspectos significativos da vida da pessoa. Por isso, desde a mais tenra idade, deve-se preocupar com uma educação que priorize todos os aspectos da vida. De acordo com Costa e Lima:

Somente as oportunidades educativas, ou seja, o ato de educar, transformam o potencial de um ser humano [...] em capacidades de ser, conviver, produzir e aprender de forma contínua. (Costa e Lima, 2002).

A palavra valor é vocábulo derivado do latim valor. Silva (1996) atribui à escola a principal responsabilidade de educar para valores, pois é nela que a crise de valores se manifesta: "sem dúvida, a escola constitui um dos centros onde essa crise valorativa se reflete e eclode". 
De fato, a educação para valores permeia as ações desenvolvidas em sala de aula e além dela. É na escola que a criança começa a ampliar suas interações interpessoais por meio das relações com os colegas e professores.

A Educação para valores a que se refere à pesquisa trata-se dos valores básicos para a convivência em sociedade, o que Pérez Serrano (2002) define como:

Cultivar as atitudes de abertura, um respeito pela diversidade, ensinando a reconhecer a injustiça, adotando medidas para superá-la, resolvendo as diferenças de maneira construtiva e passando de situações de conflito à reconciliação e à reconstrução social.

Educar as crianças para relações saudáveis, para conviver em harmonia, para serem construtoras da paz. Essa mesma autora enfatiza:

A educação para a convivência necessita de enfoques integrados e catalisadores. Implica que a educação preocupe-se com a dimensão da formação integrada de valores, conhecimentos e destrezas requeridas pela paz, a promoção dos direitos humanos, a democracia e o desenvolvimento. (Pérez Serrano, 2002)

A palavra "Educar", por sua vez, vem do latim educare, ligado a educere, verbo composto do prefixo ex (fora) + ducere (conduzir, levar), e significa literalmente 'conduzir para fora', ou seja, preparar o indivíduo para o mundo. A finalidade principal da Educação de crianças pequenas nas Escolas de Educação Infantil é propiciar oportunidades e criar condições para o desenvolvimento das crianças, por meio de uma prática educativa que favoreça o desenvolvimento de suas capacidades: físicas, cognitivas, estéticas, afetivas, de relação interpessoal e inserção social, considerando as diferentes habilidades, interesses e maneiras de aprender. É também na Educação Infantil que se inicia a preparação para a cidadania responsável e consciente.

O termo "Criança Pequena" utilizado nesta pesquisa refere-se à criança de zero a seis anos, ou seja, a criança de Educação Infantil. Não se tem conhecimento de o termo ter sido cunhado por algum autor. Em todas as produções referentes a crianças pequenas encontram-se ape- nas referências a bebês, crianças de creche ( 0 a 3 anos) ou crianças de Educação Infantil (0 a 6 anos).

Em relação à palavra "Valor" temos várias definições. E um vocábulo derivado do latim valor. Destacam-se as definições que se relacionam com a temática aqui abordada: 1. Qualidade que revela o préstimo ou serventia de algo; 2. Validade, legitimidade; 3. Importância, significação; 4. Conjunto de princípios, ideais e julgamentos morais.

O termo "Amor" pode ter várias significações, na língua portuguesa. Assim, como a maioria dos vocábulos, provém do latim. Conceitos populares traçam várias definições românticas para a palavra Amor. O conceito mais popular de amor envolve, de modo geral, a formação de um vínculo emocional com alguém, ou com algum objeto que seja capaz de receber este comportamento amoroso e enviar os estímulos sensoriais e psicológicos necessários para a sua manutenção e motivação. É uma palavra muito fascinante, utilizada e admirada em todos os idiomas. Chalita (2003) afirma: "[...] defini-lo é muito mais que uma simples demonstração de conhecimento linguístico, é antes de tudo uma empreitada desafiadora". Acrescenta:

A palavra amor vem do latim amor, que quer dizer "amizade, dedicação, afeição, ternura, desejo grande, paixão, objeto amado. O registro histórico sobre a evolução gráfica do vocábulo indicam que o termo já aparece grafado como Amur no século XIV e aamoor e hamor no século XV. (Chalita, 2003).

Neste estudo, além das numerosas acepções do dicionário, utilizar-se-á, também, a palavra Amor contida nos sábios ensinamentos de Jesus, nos Evangelhos: "[...] para que o amor com que me amaste esteja neles [...]" (Bíblia, 1990, Jó 17,26); "O meu mandamento é este: que vos ameis uns aos outros, assim como eu vos amei." (Bíblia, 1990, João 15,12).

A palavra "justiça" significa respeito à igualdade de todos os cidadãos, é um termo que vem do latim. É o principio básico de um que tem o objetivo de manter a ordem social através da preservação dos direitos em sua forma legal. É um termo abstrato que designa o respeito pelo 
direito de terceiros, a aplicação ou do seu direito por ser maior em virtude moral ou material. Segundo Aristóteles, o termo justiça denota, ao mesmo tempo, legalidade e igualdade. Assim, justo é tanto aquele que cumpre a lei (justiça em sentido estrito) quanto aquele que realiza a igualdade (justiça em sentido universal). Justiça também é uma das quatro virtudes cardinais, e, segundo a doutrina da Igreja Católica, consiste "na constante e firme vontade de dar aos outros o que lhes é devido"É a virtude da responsabilidade e da equidade.

A justiça compreende várias qualidades e exige a presença de várias condições: compreender e respeitar os direitos dos outros; hábito de cumprir as nossas obrigações; obrigação de procurar fazer o melhor que nos for possível; respeito pela autoridade legítima; saber viver com as consequências das nossas ações e erros; hábito de honrar as nossas promessas e compromissos; hábito de evitar a intromissão em assuntos alheios; dar aos outros o benefício da dúvida e respeitar o direito à presunção de inocência. (Marques, 2003).

"Bondade", do latim, bonitas, significa: 1. Benevolência, indulgência; 2. Amabilidade, cortesia; 3. Ternura, brandura. Frequentemente se usa a palavra bondade como uma inclinação para o bem, um dom pessoal. A infância é um período propício para se ensinar a bondade à criança, sobretudo pelos bons exemplos.

Este conjunto de vocábulos, nas suas mais diversas significações, constituem um rol importante na prática docente, sobretudo na dos educadores de crianças pequenas. Destaca-se, de modo especial a palavra "impregnar" que provém da palavra impraegnare, de origem latina e significa: 1. Fazer penetrar uma substância em; 2. Embeber, ensopar, encharcar; 3. Imbuir, encher; 4. Compenetrar-se. Acredita-se que os valores aprendidos na infância vão impregnar-se no mais íntimo ser destas crianças influenciando na formação de sua personalidade e nas escolhas que, ao longo de sua trajetória de vida lhes serão necessárias fazer.

Por isso é importante refletir também sobre a pessoa do educador de crianças pequenas, pessoas responsáveis pelo cuidado das crianças nesta fase mais importante de suas vidas. "Do ponto de vista da pesquisa, nas últimas décadas, vários grupos, em todo o mundo, tem investigado aspectos relativos à educação de crianças pequenas fora do lar. (Rosseti-Ferreira, et al, 2002). Rocha (1999) aponta os avanços científicos que estão produzindo bases de conhecimentos e know-how necessários para subsidiar políticas educacionais e práticas de educação e cuidado infantil de qualidade, capazes de favorecer o desenvolvimento sadio das crianças.

Diante de tantos desafios da educação, hoje, os processos precisam ser ressignificados. É necessário formar pessoas de relação que saibam valorizar-se a si mesmo, ao outro, ao meio ambiente e ao Transcendente.

\section{Definindo outros conceitos: as dimensões do cuidado em educação}

O "autocuidado", cuidado consigo mesmo (cuidado do corpo, da mente, dos sentimentos). Tanto na saúde quanto na educação se defende a necessidade de uma educação que tenha um olhar especial sobre a pessoa humana em sua totalidade. É na infância que se desenvolvem os hábitos mais saudáveis de alimentação, higiene física e mental e melhoria na qualidade de vida.

Pela experiência adquirida ao longo de nove anos trabaIhando com Educação Infantil pude perceber o quão é importante educar crianças pequenas para valores. Estes valores são impregnados em seu ser e, as crianças disseminam estes ensinamentos a seus pais e àqueles que convivem com elas.

Os cuidados, [...] são todas aquelas atitudes e procedimentos ligados à proteção e apoio necessários ao cotidiano da criança: alimentar, lavar, trocar, curar, proteger, consolar, que são integrantes do educar, mas que exigem conhecimentos e habilidades diferenciadas... (Maranhão, 1998).

De acordo com Brasil (1998):

A base do cuidado humano é compreender como ajudar o outro a se desenvolver como ser humano. Cuidar significa valorizar e ajudar a desenvolver capacidades. $\mathrm{O}$ cuidado é um ato em relação 
ao outro e a si próprio que possui uma dimensão expressiva e implica em procedimentos específicos. O desenvolvimento integral depende tanto dos cuidados relacionais, que envolvem a dimensão afetiva e dos cuidados com os aspectos biológicos do corpo, como qualidade da alimentação e dos cuidados com saúde, quanto da forma como esses cuidados são oferecidos e das oportunidades de acesso a conhecimentos variados.

O "altercuidado", cuidado do outro, das relações com o outro. Waldow (2004) salienta que "cuidar de outrem possibilita cuidar de si". E ainda acrescenta, "O cuidado deve ser nutrido, cultivado, compartilhado!" Na dimensão do cuidar do outro destacar-se-á os seguintes aspectos. 1. A relação de cuidado criança $x$ criança. 2. A relação cuidado professor $x$ criança.

[...] O cuidado nasce de um interesse, de uma responsabilidade, de uma preocupação, de um afeto, o qual, em geral, implicitamente inclui o maternar e o educar que, por sua vez, implicam ajudar a crescer (Waldow, 1998).

Cuidar do outro é função inerente à missão de mães e educadores. Waldow destaca:

[...] a cuidadora (em geral, papel atribuido à muIher) dedica-se a prover, além da atenção e do afeto o conforto e demais atividades que possibilitem o bem-estar, a restauração do corpo e da alma e a dignidade. (Waldow, 1998).

a) Relações Interpessoais: família, escola, amizade, vida afetivo-sexual. O desenvolvimento social na Educação infantil se dá, sobretudo nos jogos e brincadeiras. A criança aprende a perder, ganhar, respeitar o outro, descobrir as diferenças. Nesta fase a criança amplia seus laços de amizade, que se estende além da família, aprende a conviver com seus pares, a respeitar e ser respeitada. Este relacionamento é fundamental para a construção e fortalecimento do seu "eu".

b) Relações Sociais mais amplas: ética, cidadania, solidariedade social e sentimento humanitário. Ensinar valores para crianças pequenas não é tão fácil assim, sobretudo neste momento em que vivemos uma profunda crise de valores entre os adultos. Como ensinar ser ético se ao seu redor ela só encontra atitudes nada éticas?
Mas é missão da escola. Tarefa que requer experiência, amor e dedicação, pois, desde o nascimento a criança torna-se uma cidadã, adquire direitos e precisa aprender a conviver.

A alteridade requer a vivência da solidariedade. $\mathrm{O}$ dicionário define a "solidariedade" como: 1 . Dependência mútua entre os homens. 2. Sentimento que leva os homens a se auxiliarem mutuamente. 3. Relação mútua entre coisas dependentes. 4. Compromisso pelo qual as pessoas se obrigam umas pelas outras.

A solidariedade é uma virtude que deve impregnar todas as expressões da vida para que se desenvolva uma cultura de "solidariedade" e não apenas ações de solidariedade em momentos de catástrofes. Educar para a solidariedade é criar um sentimento de comprometimento com o bem do outro.

Chalita (2003) defende a ideia de que "ser solidário é contribuir para uma ciranda contínua que preconiza, sobretudo, um vaivém coletivo de boas ações". Segundo ele:

Solidariedade. Uma palavra de dimensões cada vez mais grandiosas. Irmã caçula - de corpo e alma - da fraternidade, da igualdade, da justiça e do amor. [...] exercício de bem-fazer. [...] Reunião de gestos, atitudes e ações capazes de tornar o mundo melhor.

O "ecocuidado", cuidado com o ambiente em que estamos inseridos, preocupação com as redes que sustentam a vida.

Sendo uma dimensão da educação, a Educação Ambiental é um processo educativo que visa formar cidadãos éticos nas suas relações com a sociedade e com a natureza. Durante a formação, cada indivíduo é levado a uma reflexão de seus comportamentos e valores pela aquisição de conhecimentos, compromisso e responsabilidade com a natureza e com as gerações futuras. (Reigada e Reis, 2004).

A Educação Ambiental para crianças pequenas deve abordar aspectos capazes de serem absorvidos por esta faixa etária. Se a criança aprende as questões básicas de respeito à natureza, à medida que for crescendo vai absorvendo e aprendendo novos conhecimentos. Práticas de educa- 
ção ambiental como: plantar uma árvore, evitar o desperdício de água e de alimentos, economizar energia elétrica, entre outras, devem ser implantadas nas escolas de Educação Infantil. As crianças pequenas respondem imediatamente a atitudes aprendidas, pois, são curiosas e gostam de sentirem-se protagonistas de uma nova proposta.

O "transcuidado", cuidado com tudo aquilo que dá sentido à nossa vida - os grandes temas da existência humana - com as questões da fé, do sentido da vida, os valores transcendentes e os grandes ideais humanos, ou seja, a dimensão transcendente do existir humano.

Montanha (2010) referindo-se à questão da espiritualidade na infância, diz: "Na mais tenra idade, a criança precisa ser acostumada a se relacionar com Deus com o objetivo de formar sua própria espiritualidade".

Não existe um conceito único de espiritualidade. $\mathrm{O}$ termo espiritualidade envolve questões quanto ao significado da vida e à razão de viver. Não pode ser limitado a tipos de crenças ou práticas religiosas. Espiritualidade envolve o mundo e tudo que o cerca. Muitas são as questões que angustiam e inquietam o ser humano: a criação do mundo, de onde viemos e para onde iremos após a morte, vida após morte, e outras questões que não encontram respostas na razão e na ciência. Neste sentido algumas destas respostas são encontradas na espiritualidade. É fundamental que a criança faça a experiência de uma espiritualidade que a leve a ter atitudes de bondade, de compaixão, de justiça. Uma espiritualidade que vai acompanhá-la ao longo de toda sua vida.

\section{Percorrendo caminhos: o que nos diz a história, a legislação e a contemporaneidade sobre o cuidado e a educação da criança pequena para valores}

Na história geral da Educação percebe-se que a Educação da infância foi menosprezada por um longo período. Na Idade Média a criança era vista como um ser insignificante, ou mesmo "um adulto em miniatura" (Ariès, 1981). Até mesmo seus trajes eram semelhantes aos dos adultos. A infância era praticamente ignorada.
Não se acreditava na inocência das crianças e nem respeitavam seus sentimentos.

Neste último século, porém, há um crescente número de pesquisas sobre crianças de Educação Infantil, além do desenvolvimento de programas mais estruturados de cuidado e educação na primeira infância, o que comprova a preocupação com educação de qualidade para a criança e a qualificação dos profissionais que trabalham com as mesmas. Como a educação da criança pequena vem ganhando relevância e destaque há uma preocupação maior com a criança, com a infância, com sua história. Ao contrário da Idade Média, agora a criança pequena ganha identidade histórica e pessoal. Esta preocupação é motivada pelas transformações rápidas e intensas do mundo contemporâneo e os impactos que estas causam na vida social e, em decorrência, o surgimento do alto índice de violência, um problema que afeta as nossas escolas, famílias, comunidades e toda a sociedade.

Convivemos com atos violentos constantemente: violência que se manifesta nas mais diversas formas causando danos na esfera familiar e social. Estas constantes mudanças culturais e econômicas afetam a vida dos jovens e dos adolescentes, mas, sobretudo, das crianças pequenas. E é deste ambiente que chegam à escola, já desde a mais tenra idade, crianças com relações afetadas e experiências dolorosas, que não sabem respeitar-se a si mesmo e ao outro como um ser em sua individualidade, crianças sem os requisitos básicos para a convivência.

$\mathrm{Na}$ contemporaneidade, muitos pesquisadores trouxeram uma nova perspectiva de olhar às crianças, passando a vê-las sob um novo ângulo. Wallon (1879-1962), médico, psicólogo e filósofo, o primeiro a buscar uma nova prática pedagógica, levando não só o corpo da criança, mas também suas emoções para dentro da sala de aula. Segundo Wallon, quatro elementos se comunicam constantemente entre si: a afetividade, o movimento, a inteligência e a formação do eu como pessoa.

A raça marcha adiante pelos pés das crianças pequenas. A criança de hoje será o cidadão de amanhã. [...] A criança é uma unidade e deve ser estudada [...], cuidada em toda a complexidade de sua conformação, e guiada na variedade sem 
fim de suas inter-relações. (THE CHILD, 1910 apud MONARCHA, 2001).

A revisão de literatura para esta pesquisa confirmou que existe uma grande escassez de pesquisas sobre a teoria do cuidar em educação. Realizou-se uma leitura flutuante dos trabalhos apresentados nas Reuniões Anuais da ANPED (2008 a 2010) visando, por meio dos aportes teóricos em pesquisas publicadas, elencar as temáticas referentes à Educação Infantil, utilizando para isto uma pesquisa quantitativa evidenciando o número de publicações do GT 07 sobre Educação de Crianças de zero a seis anos. Partindo desta análise, foi feita uma leitura flutuante dos resumos dos artigos selecionando e destacando os que abordam questões relacionadas à educação para valores (cuidado: autocuidado, altercuidado, ecocuidado e transcuidado) e também no GT 08, sobre Formação de Professores, os artigos relacionados à formação de professores de Educação Infantil. Concluindo, foram selecionados alguns artigos, que foram lidos na íntegra e que constituem um acervo significativo de referenciais a serem utilizados.

Porém, percebe-se que, apesar de ter aumentado muito, no Brasil, o interesse por se realizar pesquisas com crianças pequenas buscando compreendê-la em sua forma de ser e agir ainda são poucas as publicações sobre o "cuidado" da criança pequena. Pesquisadores, tanto na área da educação quanto da saúde, têm concentrado seus esforços em dar um novo sentido à Pedagogia da Infância, mas, olvidado a dimensão do cuidado. Há um leque de assuntos nas publicações que se referem diretamente à criança: Exclusão e inclusão, Construção de significado e sentido, Educação da criança em meio rural, Relação criança - adulto, Política Nacional de Educação Infantil, Brincar na Educação Infantil, Registros Pedagógico na Educação Infantil, Linguagem e Brinquedos.

No que se refere ao cuidado, tanto na preservação da vida física quanto na da afetiva, temas tratados tanto na saúde quanto na educação ou na psicologia ainda há muito a descobrir.

O cuidador precisa considerar, principalmente, as necessidades das crianças, que quando observadas, ouvidas e respeitadas, podem dar pistas importantes sobre a qualidade do que estão recebendo. Os procedimentos de cuidado também precisam seguir os princípios de promoção da saúde. Para se atingir os objetivos dos cuidados com a preservação da vida e com o desenvolvimento das capacidades humanas, é necessário que as atitudes e procedimentos estejam baseadas em conhecimentos específicos sobre desenvolvimento biológico, emocional e intelectual das crianças, levando em conta diferentes realidades sócio-culturais. (BRASIL, 1998).

Este novo olhar sobre a infância e a criança, a compreensão da criança como um ser em suas complexidades, singularidades e valores levam a acreditar em um novo mundo passível de convivências amigáveis onde as pessoas se respeitam e são respeitadas.

Como se sabe, são muito poucas as produções sobre a importância do cuidado da infância. Além dos artigos selecionados das Reuniões Anuais da ANPED (2008 a 2010), serão utilizados alguns teóricos que alertam sobre a importância de se educar crianças pequenas para valores, sobre as dimensões do cuidado e a importância da formação de professores. Desta forma a principal referência serão as produções do Programa Cuidar, de Belo Horizonte dos autores Isabel Maria Sampaio Oliveira Lima e Antonio Carlos Gomes da Costa (in memoriam), as teorias de Waldow.

A preocupação com um curso de Pedagogia que forme profissionais mais humanos e comprometidos também está começando a ser uma das preocupações dos pesquisadores atuais. Referindo-se ao curso de Pedagogia, Cruz (2002) destaca que "é necessário buscar uma formação humanizadora de Educadores e Educadoras". De fato, se não houver afetividade, humanidade na relação da criança com o adulto criará um distanciamento no relacionamento e, consequentemente, um bloqueio afetivo.

Segundo Chalita (2003) "há muitas formas de transmissão de conhecimentos, mas o ato de educar só se dá com afeto, só se completa com amor". Acreditando ser a escola de Educação Infantil um espaço privilegiado de educação, a presente pesquisa abordará as dimensões do cuidado, a saber, autocuidado, altercuidado, ecocuidado e transcuidado. 
Costa (2002), mentor e fundador do Programa Cuidar, defende a importância de uma educação baseada no cuidado, levando em consideração as suas diversas dimensões. Em entrevista à imprensa, em 2007, ele defende a necessidade de uma educação que vise:

Uma nova postura diante de si mesmo e de sua circunstância baseada [...] em uma ética de amor, zelo e respeito pela vida em todas as sua manifestações, que se traduz em quatro cuidados básicos. Autocuidado (cuidar de si mesmo), altercuidado (cuidar do outro), ecocuidado (cuidar do ambiente em que vive) e transcuidado (cuidar dos significados, sentidos e valores que presidem a sua existência).[...] uma educação para valores. (COSTA, 2007).

O teólogo Leonardo Boff, em seu livro, Saber Cuidar: A Ética do Humano - Compaixão pela Terra (2008) fala do cuidado em todos os âmbitos:

Hoje, na crise do projeto humano, sentimos a falta clamorosa de cuidado em toda parte. Suas ressonâncias negativas se mostram pela má qualidade de vida, pela penalização da maioria empobrecida da humanidade, pela degradação ecológica e pela exploração exacerbada da violência. Que o cuidado aflore em todos os âmbitos, que penetre na atmosfera humana e que prevaleça em todas as relações! O cuidado salvará a vida, fará justiça ao empobrecido e resgatará a Terra como pátria e mátria de todos (BOFF, 2008).

Outro destaque na teoria de Educação de Crianças foi o psicólogo bielo-russo Lev Semenovitch Vygotsky (18961934). Expoente da chamada teoria socioconstrutivista ou sociointeracionista. Segundo Vygotsky o desenvolvimento humano se dá nas trocas entre parceiros sociais, através de processos de interação e mediação.

Nenhuma forma de comportamento é tão forte quanto aquela ligada a uma emoção. Por isso, se quisermos suscitar no aluno as formas de comportamento de que necessitamos teremos sempre de nos preocupar com que essas reações deixem um vestígio emocional nesse alunado. (VYGOTSKY, 2001).

Quanto à história da legislação brasileira percebe-se avanços importantes nas questões de proteção, educa- ção e desenvolvimento da criança de zero a seis anos. A Constituição Federal de 1988 estabelece garantia efetiva dos direitos delas, determinando a Educação Infantil como "direito da criança" (art. 30, Vl e art. 211, § 2). Da mesma forma, em 1990, o Estatuto da Criança e do Adolescente (ECA - Lei n. 8.069/90), reservou uma série de direitos à criança: Direito à Vida e à Saude; à Liberdade, ao Respeito e à Dignidade, à Proteção, à Convivência Familiar e Comunitária; Direito à Educação, à Cultura, ao Esporte e ao Lazer. (ECA art. $7^{\circ}, 15^{\circ}$ ao $\left.18^{\circ}\right)$.

No campo da Educação Infantil, a LDBEN- Lei de Diretrizes e Bases da Educação Nacional, - Lei Federal n. 9394/96, promoveu mudanças muito significativas a partir do ano de 1996. Decretou a Educação Infantil como "a primeira etapa da educação Básica e tem como finalidade o desenvolvimento integral da criança de zero até seis anos de idade, em seus aspectos físico, psicológico, intelectual e social, complementando a ação da família e da comunidade" (Educacional, LEl 9.394, Seção 2, art. 29). A Educação Infantil, nas Creches e Pré-Escolas, deixou de ser vinculada à assistência social e tornou-se oficialmente reconhecida como um direito das crianças e a fazer parte da educação básica.

Em Porto Alegre, a partir da Lei Municipal 8198/98, o CME - Conselho Municipal de Educação, órgão competente para normatizar sobre as especificidades da primeira etapa da Educação Básica, a Educação Infantil, criou uma Resolução 003/2001, de 25 de janeiro de 2001, que estabelece normas para a oferta de Educação Infantil no Sistema Municipal de Ensino. A referida resolução visa regulamentar a Educação Básica, priorizando a Educação Infantil como um direito da criança. Neste sentido, Susin (2001) defende que a mesma baseia-se nos fundamentos da LDBEN e na visão das crianças como sujeitos de direitos.

Neste cenário atual, em que a criança pequena passa a ser protagonista de sua própria história e, consequentemente, vista como um ser com necessidades físicas, cognitivas, psicológicas, emocionais, espirituais e sociais é indiscutível a contribuição da educação. É por meio dela que a criança adquire novos conhecimentos e desenvolve habilidades de relacio- 
namento e convivência. Portanto, o momento histórico, requer uma educação baseada em valores, que seja capaz de construir pessoas autônomas e capazes de lidar com este mundo de transformações; Portal (2007) defende:

Uma abordagem integral do ser humano -sua inteireza- compreendendo dimensões inerentes e originais do próprio ser: social, racional, emocional, espiritual, para compreensão de seus próprios limites e para planejamento de seu desenvolvimento por meio de um pensar ousado e de uma prática integral.

Esta nova forma de educar exige ousadia e inovação. Cabe à escola educar para a convivência, para o respeito a si mesmo e ao outro, a solidariedade, a paz. Desenvolver uma nova forma de se relacionar. Buscar um novo jeito de ensinar e de aprender. Desenvolver um novo olhar sobre a criança e a infância. Ainda neste sentido, deve-se pensar na relação que deve ser estabelecida entre professor/alunos para que esta nova forma de educar realmente se efetive, para tanto Miranda (2008) destaca:

A interação professor-aluno ultrapassa os limites profissionais e escolares, pois é uma relação que envolve sentimentos e deixa marcas para toda a vida. Observamos que a relação professor-aluno, deve sempre buscar a afetividade e a comunicação entre ambos, como base e forma de construção do conhecimento e do aspecto emocional.

Segundo Rangel (1992) professor e aluno devem permear seu relacionamento com a amizade, a troca, a solidariedade e o respeito mútuo. Segundo a autora não é concebível desenvolver qualquer tipo de aprendizagem, estando em um ambiente hostil.

A partir desta ótica, pensamos ser urgente repensar a formação dos professores de crianças pequenas, pois, sendo o Educador de Educação Infantil responsável por criar um ambiente de ensino aprendizagem afetivo, saudável, prazeroso onde a relação professor-aluno seja agradável e propícia para o desenvolvimento da criança.

\section{Alguns resultados obtidos}

Para essa pesquisa, de cunho qualitativo, utilizamos para a coleta de dados Rodas de Conversa fundamentada em Cecília Warschauer. A autora salienta a importância da roda ao longo da história de nossas vidas, destacando:

\begin{abstract}
Essa configuração em roda facilita a comunicação. Os sujeitos conseguem se olhar, e, com isso, as interações acontecem com mais facilidade. Ocorrem trocas de olhares, trocas de argumentos, trocas de críticas, trocas de experiências. Quando se está em roda, as trocas acabam sendo inevitáveis; conseguimos por meio dela conhecer um pouco outro, observando seu comportamento, suas reações e manifestações. (ALBUQUERQUE e GALIAZZI," 2001).
\end{abstract}

As Rodas de conversa aconteceram sempre a partir de uma atividade lúdica realizada com as crianças, de acordo com a temática a elas apresentada no início de cada encontro, como: música, oficina de modelagem, desenho, fotografias. Esses recursos visaram contribuir para prender a atenção das crianças e extrair o melhor que elas podiam dar. A Roda de conversa é uma metodologia que dá voz às crianças.

Warschauer (1993) define o conceito de Roda de Conversa como:

Ato de reunir indivíduos com histórias de vida diferentes e maneiras próprias de pensar e sentir, de modo que os diálogos, nascidos desse encontro, não obedecem a uma mesma lógica. São, às vezes, atravessados pelos diferentes significados que um tema desperta em cada participante.

Os encontros foram agradáveis e prazerosos. As crianças participaram com entusiasmo. $\mathrm{O}$ enriquecimento maior se deu a partir das experiências vividas fora e dentro da escola, em família e outros espaços que as mesmas frequentam e que constituíram ideias muito interessantes nessa pesquisa.

A interpretação e análise das Rodas de Conversa possibilitou a obtenção de dados reais sobre como a criança de seis anos se percebe cuidada na família e na escola e como se 
torna cuidadora a partir de das atitudes dos adultos que têm a responsabilidade de cuidar dela, bem como o conceito de cuidado que já desenvolveram em seu cotidiano.

Em suma, pode-se concluir que os resultados evidenciaram que, a criança assimila e incorpora os valores aprendidos na escola, sente-se bem e cuidada no ambiente escolar. Quanto à família, algumas ainda carecem de uma maior compreensão das necessidades das crianças pequenas de serem ouvidas e cuidadas. Por meio da fala das crianças, percebeu-se que, algumas famílias não dispensam à criança o cuidado que ela necessita.

\section{Considerações finais}

Embora a Educação Infantil constitua uma modalidade importante no processo educativo e, alguns pesquisadores estarem se voltando para a investigação desta temática, a pessoa do educador de Educação Infantil ainda é muito subestimada.

É importante que este profissional seja altamente qualificado porque trabalha com a mais importante etapa do desenvolvimento humano. O professor de Educação Infantil deve ter uma atuação que promova o desenvolvimento da criança em todas as dimensões.

Neste sentido, é urgente um olhar de carinho e diferenciação para com este profissional. Além do domínio dos conhecimentos científicos básicos, este profissional precisa ter o conhecimento das etapas de desenvolvimento das crianças e todas as suas necessidades. Porém, a realidade é que, o professor de Educação Infantil, muitas vezes, não tem as habilidades necessárias para trabalhar com criança pequena. Não se prioriza a educação da infância como etapa que será a base, o fundamento de seu ser e agir por toda a vida. O professor destinado às classes de Educação Infantil, muitas vezes, é aquele que sobra.

É na infância que se desenvolvem as relações afetivas entre criança/educador e criança/criança. Portanto, o professor de Educação Infantil deveria ser um profissional com suas questões profissionais e emocionais bem resolvidas a fim de ensinar as crianças a resolverem seus próprios conflitos, estabelecerem relações harmoniosas, aprender a conviver.

Na vida da criança, o professor, bem como os pais são modelos, referências de vida para a criança. As crianças imitam o agir de pais e professores. Os valores aprendidos na Educação Infantil fundamentarão toda a sua vida. Por isso, nesta etapa, é importante a presença de um profissional que saiba valorizar o diálogo, a solidariedade, a partilha, a cooperação.

Necessitamos de um maior comprometimento com esta área de ensino, e também precisamos atentar aos principais educadores, a família, esta também, aliás, principalmente a família deve dar atenção, educar para valores, dela provem os primeiros ensinamentos e os mais relevantes, a escola como subsequente a família deve complementar este ensinamento, mas nunca esquecendo que a ela cabe auxiliar, pois os alunos estão de passagem pelos professores, os filhos não, estes são para sempre, por isso que uma carga maior é atribuída à família. 


\section{Referências}

ALBUQUERQUE, Fernanda Medeiros de; GALIAZZI, Maria do Carmo. A Formação do Professor em Rodas de Formação. R. Bras. Est. Pedag. Brasília. V.92, n 231, p. 386-398. Disponível em: http://rbep.inep.gov.br/index.php/RBEP/article/ view/1742/1609. Acesso em 17/08/2012.

ARIÈS, Philippe. História social da criança e da família. Rio de Janeiro: LCT, 1981.

BÍBLIA. Português. Bíblia Sagrada. 36ª ed. Tradução Centro Bíblico Católico. São Paulo: Paulinas, 1990.

BOFF, Leonardo. Saber cuidar: ética do humano - compaixão pela terra. $15^{\mathrm{a}}$ ed. Petrópolis/RJ: Vozes, 2008.

BRASIL. Referencial Curricular Nacional para Educação Infantil. V.1 Brasília: MEC/SEF, 1998.

CANDIOTTO, Cesar. Subjetividade e verdade no último Foucault. Trans/Form/Ação. [online]. 2008, vol.31, n¹, p.87-103. Disponível em: http://www.scielo.br. Acesso em: 10/08/2011.

CAVALCANTI, Margarida Tavares. Sobre o "dizer verdadeiro" no espaço analítico. Ágora (Rio J.) [online]. 2004, vol.7, n¹, p.55-72. Disponível em: http://www.scielo.br. Acesso em: $11 / 08 / 2011$.

CHALITA, Gabriel. Educação: a solução está no afeto. São Paulo: Gente, 2003.

COSTA, Antonio Carlos Gomes. A Ética Biofílica como fundamento de uma Educação para Valores. 2005. Disponível em: <http://www.cetrans.com.br/novo/textos/a-etica-biofilica. pdf > . Acesso em: 03/10/2011.

Entrevista à Revista Pontocom. 2007. Disponível em http://www.revistapontocom.org.br/edicoes-anteriores-entrevista/entrevista-com-antonio-carlos-gomes-da-costa. Acesso em: 20/05/2011.

; LIMA, Isabel Maria Sampaio Oliveira. Programa Cuidar. Educação para valores com base na ética biofílica. Volume 1. Belo Horizonte/MG: Modus Faciendi, 2002.

CRUZ, Maria Waleska. Saberes Epistêmico-solidários na Formação Humanizadora de Educadores e Educadoras Emancipatórios para a Escola e para além da Escola: por uma sociedade de utopia. 2002. Tese (Doutorado em Educação). PPGEdu. Pontifícia Universidade Católica do Rio Grande do Sul - PUCRS: Porto Alegre, 2002.

DALBOSCO, Cláudio Almir. O cuidado como conceito articulador de uma nova relação entre filosofia e pedagogia. Educ. Soc. [online]. 2006, vol.27, n॰97, p.1113-1135. Disponível em: http://www.scielo.br. Acesso 11/11/2011.
DELORS, Jacques. Educação: um tesouro a descobrir. São Paulo: Cortez, 1998.

EDUCACIONAL, Grupo de Pesquisas em Direito. [2012?]. Lei 9.394 de 20 de dezembro de 1996 (LDBEN). Disponível em: <http://gepede.sites.uol.com.br/LDBEN.html>. Acesso 23/02/2012.

FROTA, Mirna Albuquerque; ALBUQUERQUE, Conceição de Maria de; LINARD, Andrea Gomes. Educação popular em saúde no cuidado à criança desnutrida. Texto contexto - enferm. [online]. 2007, vol.16, n², p.246-253. Disponível em: http://www.scielo. br. Acesso em: 11/01/2009.

HENRI Wallon. 2006. Coleção grandes educadores. Direção de Izabel Galvão. São Paulo, Atta Mídia e Educação. 1 DVD (43min), son. (dublado), misto (color. - p/b).

MARANHÃO, Damaris Gomes. 0 cuidado como elo entre a saúde e a educação: estudo de caso realizado no berçário de uma creche. 1998. Dissertação (Mestrado em Educação). PPGE. Universidade Federal de São Paulo: São Paulo, 1998.

MARQUES, Ramiro. Virtudes: o que são e como se adquirem?. [2011?]. Disponível em < http://pt.scribd.com/doc/56635021/ ramiro-marques-o-novo-livro-da-educacao-do-caracter $>$. Acesso em: 18/11/2011.

MIRANDA, Elis Dieniffer Soares. A influência da relação professor-aluno para o processo de ensino-aprendizagem no contexto afetividade. In: ENCONTRO DE INICIAÇÃO CIENTÍFICA E MOSTRA DE PÓS-GRADUAÇÃO, 8, União da Vitória, 2008. Anais..., FAFIUV, 1-6.

MONARCHA, Carlos (org.). Educação da infância brasileira 1975-1983. Coleção educação contemporânea. Campinas/SP: Autores associados, 2001.

MONTANHA, Joel. A responsabilidade dos pais na formação espiritual dos filhos. 2010. Dissertação (Mestrado em Educação), IEPG. Escola Superior de Teologia: São Leopoldo, 2010.

PÉREZ SERRANO, Glória. Educação em Valores: Como educar para a Democracia. Tradução de Fátima Murad. 2. Ed. Porto Alegre: Artmed, 2002.

PORTAL, Leda Lísia Franciosi. Educação para inteireza: um (re) descobrir-se. Revista Educação, XXX (n. especial), p.285-296. 2007.

RANGEL, Ana Cristina Souza. Educação matemática e a construção do número pela criança: Uma experiência em diferentes contextos sócios-econômicos. Porto Alegre: Artes Médicas, 1992.

REIGADA, Carolina. REIS, Marília Freitas de Campos. Educação Ambiental para crianças no ambiente urbano: uma proposta de pesquisa-ação. Revista Ciência e Educação, vol. 10, n. 2. p.149159. 2004. 
REPÚBLICA, Presidência da; CIVIL, Casa; JURÍDICOS, Subchefia para assuntos. Lei no 8.069, de 13 de julho de 1990 (ECA). [2012?]. Disponível em: < http://www.planalto.gov.br/ccivil_03/leis/L8069.htm>. Acesso em: 23/02/2012.

REPÚBLICA, Presidência da; CIVIL, Casa; JURÍDICOS, Subchefia para assuntos. Constituição da República Federativa do Brasil de 1988. [2012?]. Disponível em: http://www.planalto.gov.br/ccivil_03/ Constituicao/Constitui\%C3\%A7ao.htm. Acesso em: 21/02/2012.

ROCHA, H.A.C.. A Pesquisa em Educação Infantil no Brasil: trajetória recente de consolidação de uma pedagogia. 1999. Tese (Doutorado em Educação). PPGE. Universidade Federal de Santa Catarina - UFSC: Florianópolis, 1999.

ROSSETTI-FERREIRA, M.C.; RAMON, F.; SILVA, A. P. S.. Políticas de Atendimento à crianças pequenas nos países em desenvolvimento. Cadernos de Pesquisa, [?] (115), 65-100. 2002.

SILVA, Sonia Aparecida Ignacio. Valores em Educação: a compreensão e a operacionalização dos valores na prática educativa. 3. ed. Petrópolis: Vozes, 1986.

SUSIN, Maria Otília Kroeff. Educação Infantil. Conhecendo a Resolução n 003/2001 - CME. Porto Alegre: Prefeitura Municipal de Porto Alegre - Cidade Educadora - Educação Popular, 2001.

VYGOTSKY, Lev S.. Psicologia pedagógica. São Paulo: Martins Fontes, 2001.

WALDOW, Vera Regina. Cuidado Humano: o resgate necessário. Porto Alegre: Sagra Luzzatto. 1998.

WALDOW, Vera Regina. O Cuidado na Saúde: As relações entre o eu, o outro e o cosmos. Petrópolis/ RJ: Vozes, 2004. 